\title{
METODOLOGIA PARA USO MÚLTIPLO E INTEGRADO DE FLORESTAS TROPICAIS DA AMAZÔNIA
}

\author{
Francisco José de Barros Cavalcanti ${ }^{1}$; Sebastião do Amaral Machado ${ }^{2}$; Roberto Tuyoshi Hosokawa ${ }^{2}$ \\ ${ }^{1}$ Eng. Florestal, Dr., Depto. de Ciências Florestais, UFAM, Manaus, AM, Brasil - fjbcavalcanti@ufam.edu.br \\ ${ }^{2}$ Eng. Florestal, Dr., Depto. de Ciências Florestais, Curitiba, PR, Brasil - samachado@ufpr.br - rth@japan.org.br
}

Recebido para publicação: 19/11/2007 - Aceito para publicação: 09/10/2009

\begin{abstract}
Resumo
O objetivo deste trabalho foi desenvolver um método para elaboração de planos de manejo de uso múltiplo de florestas tropicais heterogêneas. $\mathrm{O}$ método foi subdividido em quatro etapas. A primeira foi a construção de um banco de dados, com a função de armazenar as informações de todas as espécies e de seus produtos. A segunda, a organização das informações da floresta, com três funções: integrar as informações da floresta alvo do manejo, como as do inventário por amostragem e as do censo florestal; resgatar no banco de dados as informações existentes sobre as características das espécies e dos seus produtos; e processar e formatar as informações para programa de geoprocessamento. A terceira etapa foi a realização da análise da viabilidade econômica da exploração e beneficiamento dos produtos. A quarta foi distribuir as espécies fontes dos produtos em classes de manejo: na classe 1 , as espécies cujas regras de manejo já são estabelecidas técnica e legalmente; na classe 2, as espécies que necessitam do estabelecimento de procedimentos básicos ou mínimos de exploração e monitoramento; e na classe 3, os resíduos ou subprodutos da floresta cujas ações restringem-se ao registro e estatística da sua exploração. No método, o monitoramento das atividades e dos seus custos também foi tratado.

Palavras-chave: Manejo florestal; uso múltiplo; Amazônia.
\end{abstract}

\begin{abstract}
Methodology for multiple and integrated use of Amazonian tropical forests. The objective of this work was to develop a method for preparation of management plans for multiple use of tropical forests heterogeneous. The method was divided into four stages. The first, building a database with the function of storing the information of all species and their products. Second, organization of information from the forest, with three functions: to integrate information from field surveys of the forest management of the target, such as inventory by sampling and census; Recover the database the existing information on the characteristics of species and their products, and process and format the information to GIS. The third step was the analysis of the economic viability of exploitation and processing of products. The fourth was to distribute the species sources of the products of management classes: in class 1 , the species for whose management rules are already established technical and legally, in class 2 , the species that require the establishment of standardized procedures or minimum operating and monitoring and class 3 , the waste or by-products of the forest, whose actions are restricted to registration and statistics of their holdings. In the method, the monitoring activities and their costs, were also treated.

Keywords: Forest management; multiple use; Amazonian.
\end{abstract}

\section{INTRODUÇÃO}

Apesar dos esforços que têm sido realizados no sentido de conter o sistemático e regular desmatamento na Amazônia, é praticamente inevitável que as taxas sejam sempre positivas, isto é, que o desmatamento continue ocorrendo enquanto houver grandes extensões de florestas. A sua maior ou menor taxa anual continuará oscilando principalmente em função das variáveis climáticas e econômicas. As ações de comando e controle do Estado sempre terão efeito limitado no tempo e no espaço, em função da energia que demandam e da extensão territorial envolvida. 
Os apelos e campanhas sentimentais, por sua vez, continuarão a ser inócuas àqueles que investem em commodities, sejam eles grandes especuladores de bolsa de valores ou simples grileiros de terras na região. A possibilidade de reversão desse quadro será sempre a mesma, a não ser que, paralelamente ao aprimoramento de sistemas de controle e de fiscalização, sejam desenvolvidos e disponibilizados sistemas de desenvolvimento econômico e social baseados no uso e na conservação das florestas.

Ressalvadas as áreas destinadas ao não-uso ou uso indireto, cabe às demais áreas florestadas, públicas ou privadas, o papel de proporcionar o desenvolvimento economicamente viável, ecologicamente sustentável e socialmente justo da região. Tal desenvolvimento, considerando a Reserva Legal de $80 \%$ das propriedades, deve ser baseado no manejo florestal.

Embora a floresta de terra firme apresente uma infinidade de recursos aproveitáveis pela sociedade, suas riquezas estão dispersas na sua heterogeneidade. Essa característica tem sido considerada um fator limitante ao seu aproveitamento econômico. Apesar disso, muitos produtos animais e vegetais foram e são explorados isoladamente, sob formas e condições históricas distintas. A interpretação da biodiversidade como desvantagem competitiva sempre foi expressa nas políticas estatais e nas iniciativas privadas. Um histórico das políticas públicas para a região pode ser encontrado em Silva (2003).

Sistemas de manejo de florestas tropicais são fartamente descritos na literatura e podem ser obtidos em Silva (1997), Silva (1996), Higuchi (1991) e Silva (1989), dentre outros. Através desses autores e daqueles por eles citados, pode-se concluir que o manejo florestal sustentável na Amazônia é possível. Entretanto, em contraposição às técnicas de manejo que visam a simplificação do povoamento florestal através da redução do número de espécies, faz-se necessário promover o uso múltiplo da floresta, visando o aproveitamento econômico do máximo da biodiversidade existente. Esse padrão se justifica nos seguintes princípios:

a) Quanto maior for o número de espécies identificadas como possuindo algum valor comercial, maior será o número de espécies contempladas e favorecidas pelas práticas de manejo; consequentemente, menor será a tendência de a floresta manejada distinguir-se da floresta original.

b) Quanto maior for o número de espécies a serem exploradas, menos intensamente será necessário explorar cada uma delas, a fim de tornar economicamente viável e competitivo o manejo da floresta, reduzindo-se, consequentemente, o risco da quebra de alguma relação ecológica importante. Contudo, de um lado, muitas espécies têm sido tradicionalmente exploradas na Amazônia sem qualquer plano de manejo, por meio do extrativismo. De outro lado, os engenheiros florestais as desconsideram na elaboração de planos de manejo de florestas da região.

O principal argumento para a não normatização da exploração de muitos produtos florestais pelos órgãos licenciadores e para a não inclusão das respectivas espécies em planos de manejo tem sido a ausência de informações básicas sobre elas, como sua autoecologia e o seu custo de exploração. Embora esses argumentos sejam válidos, tais espécies continuam sendo exploradas, caracterizando um ciclo vicioso, no qual a tendência é o comprometimento dos estoques naturais. A alternativa a esse ciclo vicioso é considerar as informações existentes, mesmo que insuficientes, e a elas reunir estimativas baseadas em espécies ou atividades semelhantes, para concepção de estratégias mínimas de manejo.

A inserção das espécies nos planos de manejo florestal aliada à adoção de ferramentas de monitoramento que visem a obtenção de informações fidedignas oriundas da floresta sob manejo possibilitarão o constante ajuste do plano de manejo, transformando o ciclo vicioso atual num ciclo virtuoso, no qual cada vez mais espécies poderão ser contempladas.

Baseado na situação atual descrita, este trabalho objetivou desenvolver uma metodologia científica, com uso de ferramentas tecnológicas, principalmente de informática, para elaboração de planos de manejo de uso múltiplo de florestas da Amazônia.

\section{MATERIAIS E MÉTODOS}

\section{Caracterização da área de estudo}

A área de estudo foi composta por duas fazendas contíguas denominadas de São Jorge 1 e São Jorge 2, que perfazem 7.885 hectares, localizadas ao norte do município de Sena Madureira, no estado do Acre, sob as coordenadas $9^{\circ} 26^{\prime} 17^{\prime \prime}$ Sul e 68 $38^{\prime} 18^{\prime \prime}$ Oeste de Greenwich. Nela foi realizado o censo florestal em 1.000 hectares, subdivididos em 10 unidades de trabalho de 100 hectares cada uma. 
O clima da área é classificado como equatorial quente úmido, apresentando uma precipitação pluviométrica média entre 2000 e $2250 \mathrm{~mm}$ anuais, com longa estação chuvosa. O balanço hídrico apresenta oscilações ao longo do ano. No "inverno" são comuns as "friagens", fenômeno efêmero, porém muito comum na região. A "friagem" é resultado do avanço da Frente Polar e provoca brusca queda de temperatura, permanecendo por alguns dias com a média em torno de $10^{\circ} \mathrm{C}$. Os dados climatológicos registram temperaturas médias anuais variando entre $24,5^{\circ} \mathrm{C}$ e $25,5^{\circ} \mathrm{C}$, sendo julho o mês mais frio, com média de $23,3{ }^{\circ} \mathrm{C}$, e outubro o mais quente, com média de $25,8^{\circ} \mathrm{C}$. Esses dados demonstram a pequena amplitude térmica da região. A umidade relativa apresenta-se em níveis elevados durante todo o ano, com médias mensais em torno de $80-90 \%$, sem significativas oscilações no decorrer do ano (RADAMBRASIL, 1976).

A área possui variabilidade quanto às suas características geológicas, hidrográficas e geomorfológicas. Encontram-se várias classes de solos, que se apresentam bem distribuídos, desde as margens do Rio Iaco, onde predominam os solos hidromórficos, até as nascentes dos pequenos igarapés, onde são observados principalmente os argissolos.

As áreas deste estudo estão inseridas na bacia hidrográfica do Rio Purus, estando as duas fazendas situadas entre duas unidades morfoestruturais, a Depressão Rio Acre-Rio Javari e o Planalto Rebaixado da Amazônia Ocidental. A primeira se caracteriza por constituir uma extensa superfície rebaixada, apresentando um baixo nível topográfico, com altimetria média variando em torno de $200 \mathrm{~m}$, não apresentando, porém, grandes irregularidades topográficas. Sua feição geomorfológica é composta por colinas tipo C11 com interflúvios de dimensões inferiores a $250 \mathrm{~m}$ e drenagem pouco entalhada. Já o Planalto Rebaixado da Amazônia Ocidental tem como característica a existência de áreas aplainadas ainda conservadas e relevos dissecados em interflúvios tabulares. Essa unidade já apresenta um nível topográfico mais elevado, com valores altimétricos variando de 250 a 300 metros.

\section{Fisionomias vegetais}

A área da fazenda é predominantemente composta por floresta aberta, com variações de composições florestais e formas de relevo conforme tabela 1.

Tabela 1. Fisionomias vegetais da área de estudo identificadas em imagens de satélite Landsat 5. Table 1. Identified vegetable physiognomies in the study area by Landsat 5 satellite images.

\begin{tabular}{lcc}
\hline Tipologia & Área (ha) & \% Fazenda \\
\hline Desmatamento & 100,11 & $1 \%$ \\
$\begin{array}{l}\text { Floresta Ombrófila Aberta Aluvial com palmeiras + Floresta Ombrófila Densa } \\
\text { Aluvial Dossel Emergente }\end{array}$ & 246,84 & $3 \%$ \\
$\begin{array}{l}\text { Floresta Ombrófila Aberta Aluvial com palmeiras + Floresta Ombrófila Densa } \\
\text { Aluvial dossel uniforme }\end{array}$ & 120,55 & $2 \%$ \\
$\begin{array}{l}\text { Floresta Ombrófila Aberta Terras Baixas com bambus + Floresta Ombrófila } \\
\text { Densa Terras Baixas dossel emergente }\end{array}$ & $4.087,41$ & $52 \%$ \\
$\begin{array}{l}\text { Floresta Ombrófila Densa Terras Baixas dossel emergente + Floresta Ombrófila } \\
\text { Aberta Terras Baixas com bambus }\end{array}$ & $3.278,79$ & $42 \%$ \\
Pastagens + vegetação secundária antrópica & 51,48 & $1 \%$ \\
\hline Total & $7.885,18$ & $100 \%$ \\
\hline
\end{tabular}

Fonte: Funtac (2002).

\section{Inventário amostral}

O inventário florestal diagnóstico da área foi realizado por Funtac (2002). Nele foram identificadas 254 espécies em dois níveis de abordagem, $1 \%$ e $0,02 \%$ de intensidade amostral, respectivamente. No nível 1, com unidades de amostra de 10 x $500 \mathrm{~m}$, foram medidas todas as árvores com DAP $\geq 20 \mathrm{~cm}$. Delas foram registrados o DAP, nome vulgar, forma de vida ou hábito (árvore, palmeiras, cipós e arbustos) e a qualidade de fuste. No nível 2, em unidades de amostra de 10 x $10 \mathrm{~m}$, foram medidos os vegetais de $5 \mathrm{~cm} \leq \mathrm{DAP}<20 \mathrm{~cm}$, registrando-se as mesmas informações do nível 1 .

\section{Censo florestal}

Para a realização do censo florestal, isto é, inventário a $100 \%$, foram abertas picadas paralelas, distantes $50 \mathrm{~m}$ entre si. Foram registradas todas as árvores com DAP $\geq 40 \mathrm{~cm}$. Na picada foram fixadas estacas a cada $25 \mathrm{~m}$, para o georreferenciamento das árvores. Na ficha de campo, foram ainda registradas 
a data, identificador, anotador, unidade de trabalho, faixa, ficha, azimute do caminhamento e informações quanto à variação topográfica e da vegetação. Para o microzoneamento, foram registradas as seguintes informações de cada árvore: número, nome vulgar, coordenadas X e Y, CAP ou DAP, altura comercial, estado físico (viva, morta, em pé, caída, quebrada, oca e outras) e classe de qualidade do fuste, expresso pelo número de toras de $4 \mathrm{~m}$ que o mesmo poderia oferecer.

\section{Características tecnológicas e ecológicas das espécies}

As características autoecológicas foram obtidas em Piña-Rodrigues et al. (1990), Freitas (2004) e através de entrevistas com mateiros (identificadores botânicos) da Fundação de Tecnologia do Estado do Acre (FUTAC) e do Centro dos Trabalhadores da Amazônia (CTA). As características tecnológicas das madeiras das espécies que compuseram o Banco Geral de Dados foram obtidas em Chichignoud et al. (1990), Ibama/Lpf (1997), IBDF (1988), IBDF/CNPq (1981), INA (1991), IPT (1989a), Rizzini (1990) e Sudam/IPT (1981).Vale ressaltar que tais publicações não obedecem a um mesmo padrão de apresentação da informação. Dessa forma, para montagem do banco de dados, foi desenvolvida uma estrutura híbrida, baseada no conjunto das publicações consultadas.

\section{Investimentos, custos operacionais e preços de produtos}

Os investimentos e os custos operacionais da exploração das espécies fornecedoras de tora foram obtidos em Homes et al. (2002). As receitas, por sua vez, foram atualizadas baseadas nos preços praticados pelas empresas na região de Paragominas (PA) e de São Félix do Xingu. Os preços dos produtos da floresta, comercializados em feiras livres e outros mercados, foram obtidos em Braz et al. (2002) e em pesquisa de campo. Os investimentos e custos operacionais para implantação e funcionamento das usinas de beneficiamento foram obtidos em MMA/Suframa/Sebrae/GTA (1998).

Entretanto, os valores dos custos e dos benefícios de tais investimentos não foram apresentados pela bibliografia com a discriminação necessária para a aplicação do método proposto. Consequentemente, eles precisaram ser adaptados. Saliente-se que os valores de produção e produtividade utilizados devem ser considerados apenas como ilustrativos do método, uma vez que não foram produzidos ou testados na floresta alvo do estudo. Da mesma forma, a coleta de preços praticados no mercado dos diferentes produtos florestais visou apenas o teste do algoritmo do método.

\section{Processamento dos dados}

O volume comercial das árvores foi estimado através do modelo de Schumacher, adaptado por Cavalcanti (1992), que testou quatro modelos com dados da Floresta Estadual do Antimary, localizada próxima à área de estudo. Segue a descrição desse modelo:

$$
\mathrm{V}=0,000105 * \mathrm{DAP}^{1,9570} * \mathrm{H}^{0,7515}
$$

Em que: $\mathrm{V}=$ volume comercial com casca;

DAP $=$ diâmetro a 1,30 metros do solo, em centímetros.

$\mathrm{H}=$ altura comercial, em metros.

O procedimento para concepção do método proposto foi subdividido em quatro etapas, a saber:

I. Banco de dados, com duas funções básicas: armazenar as informações de qualquer espécie conhecida e de seus produtos, tais como suas características ecológicas, tecnológicas e econômicas, e expressar o nível de conhecimento das espécies, dos produtos e das variáveis das espécies.

II. Informações da floresta, com três funções principais: a primeira é a de integrar as informações dos levantamentos de campo da floresta alvo do manejo, isto é, do inventário por amostragem, do censo florestal e de outras fontes; a segunda função é buscar no banco de dados as informações existentes sobre as características das espécies, bem como dos seus produtos; a terceira função trata dos processamentos e formatação das informações para transferência ao programa de geoprocessamento e consequente confecção dos mapas necessários ao manejo florestal.

III. Análise de investimentos, com a função de avaliar a viabilidade econômica dos diferentes produtos identificados na floresta, tanto do setor primário - extrativismo - quanto do setor secundário, isto é, das usinas de beneficiamento.

IV. Classes de manejo, com a função de distribuir as espécies fontes e seus produtos em três classes de 
manejo distintas. Na classe 1 , as espécies cujas regras de manejo já são estabelecidas técnica e legalmente. Na classe 2, as espécies que necessitam do estabelecimento de procedimentos básicos ou mínimos de exploração e monitoramento, uma vez que não estão definidos na literatura. Finalmente, na classe 3 foram destinados os resíduos ou produtos da floresta, cuja política de manejo restringe-se ao registro e estatística da sua exploração.

A análise de investimentos foi realizada por meio da aplicação dos métodos clássicos, citados por Souza; Clemente (2001) e Piña-Rodrigues (1990), e outros: valor presente líquido (VPL), valor presente líquido anualizado (VPLa), índice benefício custo (IBC), retorno adicional sobre o capital investido (ROIA), taxa interna de retorno (TIR) e tempo de retorno do capital (Payback).

Espécies tradicionalmente impactadas pela exploração madeireira foram inseridas no plano de manejo, independentemente da quantidade ou da qualidade das informações disponíveis sobre elas. Para tanto, foram inseridas estimativas conservadoras das variáveis faltantes no banco de dados, quando necessárias para o processamento das rotinas desenvolvidas. Por exemplo, no caso de bromélias e orquídeas, foi estimada a abundância de 0,1 indivíduo por árvore abatida.

\section{RESULTADOS E DISCUSSÃO}

\section{Banco de dados}

Foram catalogadas 906 espécies, classificadas em sete formas de vida. Delas foram registradas 156 aplicações tecnológicas distribuídas em 30 grupos de uso. Com relação às informações ecológicas das espécies, foram selecionadas 30 variáveis para a classificação do seu respectivo nível de conhecimento. O nível de conhecimento (NC) de cada espécie foi definido como sendo o número de variáveis preenchidas no banco de dados acerca da mesma, sobre o total de variáveis. Em porcentagem, o NC seria de $100 \%$ para as espécies com as 30 variáveis preenchidas no banco de dados. Apenas uma espécie atingiu 76,7\%, e quatro atingiram 70,0\% de NC. Das 906 espécies cadastradas, 142 apresentaram $50 \%$ e 16 espécies atingiram apenas 3,3\% de NC (Figura 1).

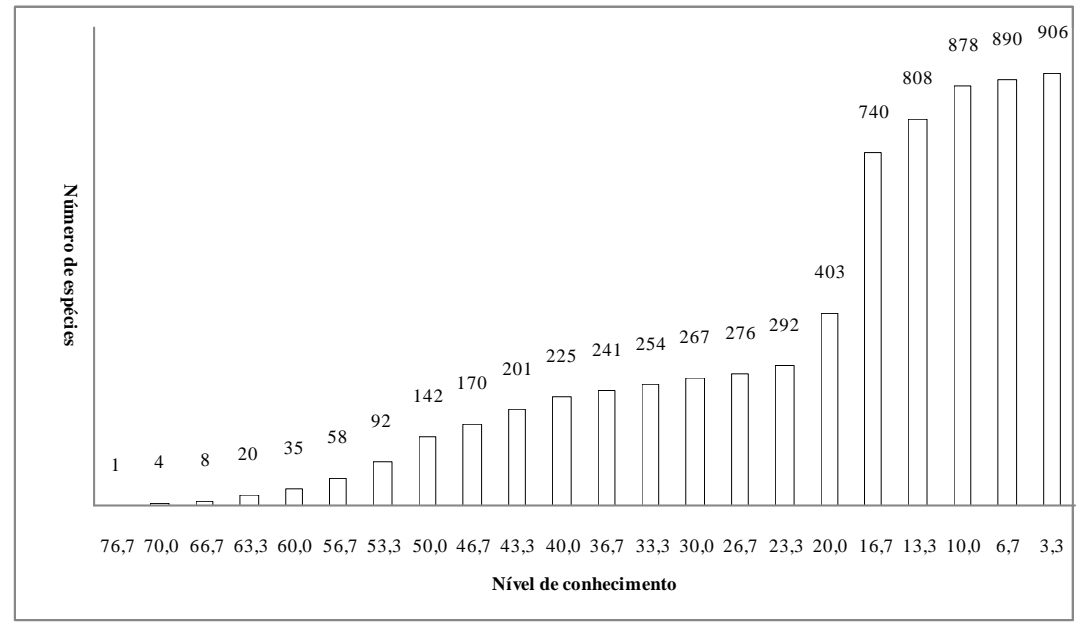

Figura 1. Nível de conhecimento das espécies vegetais do banco de dados.

Figure 1. Plant species knowledge level of the data bank.

\section{Informações da floresta}

Nos 1.000 hectares inventariados, foram registradas 16.652 árvores, distribuídas em 151 espécies. No inventário diagnóstico, por sua vez, foram registradas 254 espécies. A mesclagem das duas listas resultou em 302 espécies. A essa lista foram adicionados 13 itens, dos quais, quatro referem-se a resíduos da floresta ou da exploração da madeira e nove são espécies que, embora não tenham sido identificadas no inventário amostral ou no censo florestal, ocorrem na área, são impactadas pela exploração da madeira e possuem potencial econômico, tais como bromélias, orquídeas e cipós. 
O termo perfil é utilizado nesse trabalho com a denotação de contorno, silhueta, o que significa uma análise não aprofundada acerca das variáveis ecológicas das espécies da floresta. O nível de conhecimento das espécies da área de manejo foi obtido da mesma forma que o das demais espécies do banco de dados. Nesse caso, $3 \%$ das variáveis foram respondidas para todas as 311 espécies.

Com relação aos usos ou aplicações industriais das espécies da floresta estudada, o banco de dados continha informação sobre 194, ou $62 \%$ do seu total. O pau-d'arco-amarelo, com 51 usos ou aplicações registradas, foi a espécie mais importante nesse aspecto. Ao mesmo tempo, 86 espécies continham 10 ou mais aplicações e outras 36 espécies só continham uma aplicação registrada.

Como previsível, madeira em tora para serraria apresentou o maior número de espécies-fonte. Vale destacar que, do total de 126 aplicações/produtos identificados, 83\% apresentaram mais de uma espécie-fonte. A lista dos produtos passíveis de exploração foi composta por aqueles que atenderam a três pré-requisitos:

a) no caso de madeira, ter indivíduos da espécie-fonte registrados no censo florestal com tamanho maior ou igual ao DAP mínimo de corte;

b) ter preço definido, isto é, no mínimo uma indicação de mercado;

c) ter a tecnologia de produção registrada e mensurada técnica e financeiramente (para os produtos beneficiados em usina).

O banco de dados apresentou 12 aplicações ou produtos que atenderam aos pré-requisitos citados, os quais possuem 156 espécies como fonte na floresta, assim distribuídas: tora para serraria (130), tora para laminadora (12), plantas ornamentais (7), sementes (6), cascas de uso diverso (6), cipós (2), seiva (1), poste (1), óleo in natura (1), látex líquido (1), casca antiácida (1), casca antiinflamatória (1).

Entretanto, tendo em vista que um mesmo produto de uma determinada espécie pode ter características, preço e mercado diferente de outra, tal como a madeira para serraria, as 12 aplicações ou produtos foram tratados distintamente, de acordo com a sua espécie-fonte. Tendo em vista que a informação de produtos, espécies-fonte e preços de venda não são suficientes para a definição de quais efetivamente devam ser explorados, foi avaliado se o valor obtido pela sua venda cobriria com vantagem o custo da sua exploração. Vale salientar a fragilidade desses resultados, em função da precariedade das informações adquiridas, muitas vezes de apenas uma fonte, como no caso dos preços das cascas vendidas em bancas de feira. Outras vezes, a fragilidade consiste na origem da informação da produção e da produtividade, como no caso do custo da exploração da madeira, que foi obtido em pesquisa realizada em área com topografia e floresta diferentes. Contudo, este trabalho não se propôs a comprovar a viabilidade econômica da exploração ou do beneficiamento de um ou outro produto. Seu objetivo é apresentar a metodologia, ou seja, propor uma forma de organizar e tratar a informação.

\section{Análise de investimentos}

Essa seção do método foi dividida em 2 partes: setor primário e setor secundário. Para a análise financeira, os fluxos de caixa do setor primário limitaram-se a um ou dois anos, o tempo entre a identificação do recurso na floresta e a sua comercialização. Exceção apenas no caso da madeira em tora, cujo tempo entre o censo florestal, o corte de cipós e a comercialização foi de três anos. A tabela 2 apresenta exemplos dos indicadores financeiros dos produtos do extrativismo que compõem o setor primário da produção.

Os custos do inventário por amostragem, do censo florestal, da construção das estradas, pátios, mapeamentos e todos os outros pagos pela exploração da madeira não foram contabilizados no fluxo de caixa dos demais produtos do setor primário. De acordo com a tabela 2, a catana, ou raiz tabular, utilizada para construção de jiraus ou tampas de mesas rústicas, apresentou uma das melhores performances nos índices financeiros, e o látex líquido da seringueira está entre os que apresentaram os piores resultados.

A tabela 3 apresenta os indicadores financeiros do setor secundário. Uma vez que os estabelecimentos industriais serão abastecidos pela matéria-prima fornecida pelo manejo florestal, o período de investimento considerado para todos foi de 27 anos, isto é, o ciclo de corte da madeira mais dois anos de pré-investimento. A taxa de mínima atratividade (TMA) considerada foi de $12 \%$ ao ano. 
Tabela 2. Exemplos de indicadores financeiros de produtos do setor primário da área de estudo.

Table 2. Examples of financial indicators of products of the primary sector from the study area.

\begin{tabular}{|c|c|c|c|c|c|c|c|}
\hline Produto & VPL & VPLa & VPLI & VPLB & IBC & ROIA & TIR \\
\hline Casca de cumaru & 15,37 & 9,09 & 8,76 & 17,86 & 2,04 & 42,76 & 51,05 \\
\hline Casca de sucuba & 15,37 & 9,09 & 8,76 & 17,86 & 2,04 & 42,76 & 51,05 \\
\hline Cipó-titica & 7,83 & 4,63 & 8,76 & 13,39 & 1,53 & 23,63 & 26,05 \\
\hline Galho para energia & 3,56 & 2,1 & 8,61 & 10,71 & 1,24 & 11,55 & 11,9 \\
\hline Catana para jirau & 64,86 & 38,38 & 6,27 & 44,64 & 7,12 & 166,9 & 179,21 \\
\hline Látex de seringueira & $-0,29$ & $-0,17$ & 2,49 & 2,32 & 0,93 & $-3,52$ & $-0,1$ \\
\hline Óleo de copaíba & 181,19 & 75,44 & 4,28 & 79,72 & 18,61 & 165,02 & 12,93 \\
\hline Bromélia & 37,36 & 22,1 & 4,68 & 26,79 & 5,72 & 139,2 & 28,91 \\
\hline Samambaia & 52,45 & 31,03 & 4,68 & 35,71 & 7,63 & 176,21 & 40,53 \\
\hline Antúrio & 22,27 & 13,18 & 4,68 & 17,86 & 3,81 & 95,31 & 17,28 \\
\hline Acariquara & 151,4 & 63,03 & 8,71 & 71,75 & 8,23 & 101,94 & 6,44 \\
\hline $\begin{array}{l}\text { Seiva do sangue-de- } \\
\text { boi }\end{array}$ & 181,19 & 75,44 & 4,28 & 79,72 & 18,61 & 165,02 & 12,93 \\
\hline Coco de açaí & 32,83 & 19,43 & 4,68 & 24,11 & 5,15 & 126,93 & 25,42 \\
\hline Semente de mogno & 154,61 & 91,48 & 4,18 & 95,66 & 22,89 & 378,4 & 63,79 \\
\hline Substrato de vasos & 127,67 & 75,54 & 4,18 & 79,72 & 19,07 & 336,72 & 110,3 \\
\hline Tora de bajão & 151,4 & 63,03 & 8,71 & 71,75 & 8,23 & 101,94 & 6,44 \\
\hline Tora de farinha-seca & 151,4 & 63,03 & 8,71 & 71,75 & 8,23 & 101,94 & 6,44 \\
\hline Tora de peroba & 151,4 & 63,03 & 8,71 & 71,75 & 8,23 & 101,94 & 6,44 \\
\hline Tora de corrupixá & 151,4 & 63,03 & 8,71 & 71,75 & 8,23 & 101,94 & 6,44 \\
\hline Tora de abiurana-abiu & 151,4 & 63,03 & 8,71 & 71,75 & 8,23 & 101,94 & 6,44 \\
\hline
\end{tabular}

Tabela 3. Indicadores financeiros dos investimentos no setor secundário da área de estudo.

Table 3. Financial indicators of investments in the secondary sector of the study area.

\begin{tabular}{|c|c|c|c|c|c|c|c|c|}
\hline Nome & VPL & VPLa & VPLI & VPLB & IBC & $\begin{array}{c}\text { ROI } \\
\text { A }\end{array}$ & TIR & $\begin{array}{c}\text { Pay } \\
\text { back }\end{array}$ \\
\hline Polpa de açaí & 1.927 .898 & 241.457 & 3.154 .778 & 3.396 .236 & 1,08 & 0,26 & 21,64 & 7,08 \\
\hline Couro vegetal & 3.760 .476 & 470.977 & 1.673 .513 & 2.144 .489 & 1,28 & 0,89 & 102,52 & 1,10 \\
\hline Plantas ornamentais & 7.498 .926 & 939.194 & 2.579 .357 & 3.518 .551 & 1,36 & 1,12 & 143,37 & 0,77 \\
\hline
\end{tabular}

A fábrica de polpa de açaí e o óleo essencial, resina e óleo-resina de copaíba foram os que apresentaram as piores performances. A fábrica de bijuterias de marfim-vegetal, por sua vez, foi a que apresentou os melhores resultados, de acordo com os valores considerados. Em menor ou maior grau, todas as usinas de beneficiamento testadas foram aprovadas pelos indicadores financeiros. Novamente destaca-se a falta de informação precisa sobre a quantidade estimada da produção e a capacidade de absorção do mercado.

\section{Classes de manejo}

No sentido de compatibilizar o manejo florestal com o perfil econômico ecológico das espécies, foram propostas três classes de manejo, cujas características são descritas na tabela 4 . 
Tabela 4. Classes de manejo para uso múltiplo das florestas.

Table 4. Management classes for multiple use of the forests.

\begin{tabular}{|c|c|c|c|}
\hline Características & Classe 1 & Classe 2 & Classe 3 \\
\hline Produtos característicos & $\begin{array}{l}\text { Madeira em tora para } \\
\text { serraria, para } \\
\text { laminadora e galhos }\end{array}$ & $\begin{array}{c}\text { Plantas ornamentais, } \\
\text { sementes, cipós e outras } \\
\text { espécies atingidas pela } \\
\text { exploração madeireira }\end{array}$ & $\begin{array}{c}\text { Pau, fustes ocos caídos e } \\
\text { outros resíduos da floresta ou } \\
\text { das espécies contempladas } \\
\text { nas classes } 1 \text { e } 2\end{array}$ \\
\hline Volume de produção & Alto & Médio a baixo & Médio a baixo \\
\hline Manejo da espécie fonte & Estabelecido & $\begin{array}{l}\text { Limitado, de poucas } \\
\text { espécies e apenas em } \\
\text { alguns estados }\end{array}$ & $\begin{array}{c}\text { Dispensável por ser } \\
\text { contemplado nas outras } \\
\text { classes }\end{array}$ \\
\hline Normatização do manejo & Estabelecido & $\begin{array}{l}\text { Limitado, de poucas } \\
\text { espécies e apenas em } \\
\text { alguns estados }\end{array}$ & Não estabelecido \\
\hline $\begin{array}{l}\text { Política de manejo das } \\
\text { espécies }\end{array}$ & $\begin{array}{c}\text { De acordo com a norma } \\
\text { vigente }\end{array}$ & $\begin{array}{l}\text { Limitar a exploração e } \\
\text { monitorar a população } \\
\text { remanescente }\end{array}$ & $\begin{array}{c}\text { Registrar apenas a } \\
\text { estatística da exploração }\end{array}$ \\
\hline $\begin{array}{l}\text { Complexidade da } \\
\text { exploração }\end{array}$ & $\begin{array}{l}\text { Alta, equipes } \\
\text { específicas }\end{array}$ & $\begin{array}{c}\text { Média a baixa, equipes } \\
\text { polivalentes }\end{array}$ & $\begin{array}{c}\text { Média a baixa, equipes } \\
\text { polivalentes }\end{array}$ \\
\hline $\begin{array}{l}\text { Infraestrutura da } \\
\text { exploração }\end{array}$ & Própria & $\begin{array}{l}\text { Aproveitamento da } \\
\text { classe } 1\end{array}$ & $\begin{array}{l}\text { Aproveitamento das } \\
\text { classes } 1 \text { e } 2\end{array}$ \\
\hline
\end{tabular}

A divisão das espécies em classes de manejo visa a maximização do uso da floresta, uma vez que a legislação e o nível de informação e de importância das diferentes espécies e produtos não permitiriam adequá-los numa única proposta de manejo, tal como acontece atualmente na exploração das espécies arbóreas para produção de madeira.

O mapeamento da floresta (árvores, topografia, hidrografia) e a infraestrutura construída na área, uma vez que são custeados pela exploração da madeira da classe 1 , possibilitarão ou otimizarão a exploração dos produtos das demais classes. A tabela 5 apresenta a distribuição dos produtos por classe de manejo.

As classes obtiveram uma quantidade relativamente semelhante de produtos, embora a quantidade de espécies e volume de produção seja muito maior na classe 1 , em função do produto madeira.

\section{Classe 1 de manejo}

Nessa classe, quatro produtos: tora para laminadora, tora para serraria, postes e galhos são fornecidos por 143 espécies. Os três primeiros foram registrados e dimensionados por meio do censo florestal. O manejo das espécies-fonte para a sua produção está fartamente descrito na bibliografia e nas normas legais.

Copas (galhos)

O volume de galhos, provenientes das copas das árvores a serem abatidas, não foi dimensionado no censo, porém modelos para a estimativa de colheitas futuras poderão ser desenvolvidos após a primeira exploração, instruindo o banco de dados com informação da própria floresta. A colheita dos galhos com diâmetro maior ou igual a $10 \mathrm{~cm}$ deve ser realizada por equipes independentes, compostas por um motosserrista e dois ajudantes.

Logo após o abate das toras, a copa de cada árvore deverá ser seccionada, de forma a se separarem os grandes galhos, que poderão ser arrastados pelo skidder, quando conveniente. O seccionamento da copa visará também diminuir a sua ramificação, de forma a reduzir danos à vegetação lateral da picada quando do seu arraste. Galhos menores deverão ser seccionados em comprimento de até dois metros e transportados por carreta arrastada por um pequeno trator, que transitará pelas picadas já abertas para o arraste das toras. 
Tabela 5. Produtos por fonte de informação e por classe de manejo da área.

Table 5. Products per information source and per management class of the area.

\begin{tabular}{|c|c|c|c|c|c|}
\hline \multirow{2}{*}{$\begin{array}{l}\text { Classe de } \\
\text { manejo }\end{array}$} & \multirow[b]{2}{*}{ Produto/aplicação } & \multirow{2}{*}{$\begin{array}{l}\text { Número de espécies } \\
\text { fonte }\end{array}$} & \multicolumn{3}{|c|}{ Fonte da quantificação } \\
\hline & & & Censo florestal & $\begin{array}{c}\text { Inventário por } \\
\text { amostragem }\end{array}$ & $\begin{array}{l}\text { Outras } \\
\text { fontes }\end{array}$ \\
\hline \multirow[t]{4}{*}{1} & Galho para energia & 1 & & & 1 \\
\hline & Postes & 1 & 1 & & \\
\hline & Tora para laminadora & 12 & 12 & & \\
\hline & Tora para serraria & 130 & 130 & & \\
\hline \multirow[t]{7}{*}{2} & Casca (uso diverso) & 1 & & & 1 \\
\hline & Cipó & 2 & & 1 & 1 \\
\hline & Látex líquido & 1 & 1 & & \\
\hline & Óleo in natura & 1 & 1 & & \\
\hline & Planta ornamental & 7 & & & 7 \\
\hline & Seiva (antiácida) & 1 & & 1 & \\
\hline & Semente & 5 & 3 & 2 & \\
\hline \multirow[t]{6}{*}{3} & $\begin{array}{l}\text { Casca (anti- } \\
\text { inflamatória) }\end{array}$ & 1 & 1 & & \\
\hline & $\begin{array}{l}\text { Casca (protetor } \\
\text { hepático) }\end{array}$ & 1 & 1 & & \\
\hline & Casca (uso diverso) & 5 & 4 & 1 & \\
\hline & Jirau & 1 & 1 & & \\
\hline & Substrato de vasos & 1 & & & 1 \\
\hline & Vaso de plantas & 1 & & & 1 \\
\hline
\end{tabular}

\section{Classe 2 de manejo}

Os produtos dessa classe são fornecidos por 18 espécies. São eles: as sementes (de açaí, castanheira, jarina, jatobá, mogno e sucupira-amarela), as plantas ornamentais (bromélias, orquídeas, samambaias e ouras), os cipós (cipó-unha-de-gato, ambé e titica), o látex da seringueira e o óleo de copaíba. A permanente atualização do banco de dados com as informações obtidas da floresta após a primeira exploração permitirá que essa classe assuma papel cada vez mais importante no leque de produtos oferecidos pela floresta. Em princípio, a exploração das plantas ornamentais e dos cipós deverá se restringir às existentes nas copas das árvores abatidas para exploração madeireira. A permanente atualização do banco de dados com as informações obtidas da floresta após a primeira exploração permitirá que essa classe assuma papel cada vez mais importante no leque de produtos oferecidos pela floresta.

\section{Sementes}

A exploração de sementes dependerá da localização dos indivíduos (quando registrados no censo florestal ou não), do método de coleta (se no solo ou por escalada), do número de porta-sementes em relação à população da espécie (no caso de espécies exploradas também para produção de madeira), da destinação da semente (se para consumo, artesanato ou propagação) e da característica específica (se ortodoxa ou recalcitrante). A tabela 6 apresenta exemplo da aplicação dessas informações, visando o agrupamento das afins.

Mogno, sucupira e jatobá terão a produção de sementes limitada aos indivíduos definidos como porta-semente. Essa definição deverá ser realizada após a atividade de abate de árvores, porque as árvores ocas, excluídas do abate, não são necessariamente inferiores geneticamente e, portanto, podem cumprir o papel de produtoras de sementes. 
Tabela 6. Características das espécies florestais cujas sementes serão exploradas.

Table 6. Characteristics of the forest species whose seeds are exploited.

\begin{tabular}{|c|c|c|c|c|c|c|}
\hline Espécie-fonte & Sujeita a abate & $\begin{array}{l}\text { Método de } \\
\text { coleta }\end{array}$ & Sexo & $\begin{array}{c}\text { Uso } \\
\text { principal }\end{array}$ & Longevidade & Localização \\
\hline Açaí & Não & escalada & monoica & consumo & ortodoxa & a definir \\
\hline Jarina & Não & no solo & monoica & consumo & ortodoxa & a definir \\
\hline Castanheira & Não & no solo & hermafrodita & consumo & recalcitrante & $\begin{array}{l}\text { definida no } \\
\text { censo } \\
\text { florestal } \\
\text { definida no }\end{array}$ \\
\hline Mogno & Sim & escalada & hermafrodita & propagação & recalcitrante & $\begin{array}{l}\text { censo } \\
\text { florestal }\end{array}$ \\
\hline Sucupira & $\operatorname{Sim}$ & escalada & hermafrodita & propagação & recalcitrante & $\begin{array}{l}\text { censo } \\
\text { florestal }\end{array}$ \\
\hline Jatobá & Sim & no solo & hermafrodita & consumo & recalcitrante & $\begin{array}{c}\text { definida no } \\
\text { censo } \\
\text { florestal }\end{array}$ \\
\hline
\end{tabular}

Açaí e jarina, embora não apresentem diâmetros para serem registradas no censo florestal, deverão ter suas manchas registradas no microzoneamento, tais como a rede hidrográfica e a topografia.

Açaí, jarina e castanheira não estão sujeitas ao abate, portanto todos os indivíduos registrados serão potencialmente fornecedores de sementes. Açaí, mogno e sucupira são espécies cujas sementes são coletadas antes do início da dispersão. Portanto, precisam de equipamento especial para sua coleta. Jarina, castanheira e jatobá, por sua vez, podem ser coletadas no solo.

No caso de espécies arbóreas, a exploração das sementes será realizada na intensidade aproximada de 50\% do total encontrado. Todas as espécies constantes na tabela 6 são hermafroditas ou monoicas, o que indica que todos os indivíduos são potencialmente fornecedores de sementes, porém, na medida em que mais espécies entrem na lista de produtoras de sementes comerciais, a localização dos indivíduos produtores assumirá maior relevância.

Uso principal e longevidade

Em função de o mogno e a sucupira serem espécies cujo uso principal da semente é a propagação, e considerando também que suas sementes são recalcitrantes, a sua comercialização deverá ocorrer antes da colheita, para que sejam apropriadamente acondicionadas e remetidas com brevidade. Mogno, sucupira, castanheira e jatobá são espécies registradas no censo florestal, portanto a sua localização está definida. Jarina e açaí, por sua vez, deverão ser mapeadas todas as vezes que forem encontradas durante as atividades de campo, se suas manchas não tiverem sido registradas no censo. A quantidade de sementes coletadas de cada indivíduo, bem como cada etapa da sua exploração, deverão ser registradas para posterior avaliação da produção, da produtividade e dos custos da exploração, com dados da própria área.

Cipós e plantas ornamentais

O cipó-unha-de-gato é a única espécie desse grupo registrada no inventário por amostragem. O cipó-ambé, o cipó-titica e os sete tipos de plantas ornamentais, mesmo não tendo sido registrados nas unidades de amostra do inventário, ocorrem na área do manejo. A quantificação prévia da abundância dessas espécies, dentro de um intervalo de confiança aceitável, não pode ser medida ou estimada a não ser por um sistema de amostragem cujo custo dificilmente seria pago pela sua exploração. Uma alternativa seria a adoção do registro dos cipós presos às árvores durante a realização do censo florestal.

As plantas ornamentais e as plantas-mães dos cipós deverão ser acondicionadas em paneiros forrados com folhas de palmeira, para evitar insolação, e encaminhadas para o viveiro florestal. No viveiro florestal, as plantas são acondicionadas e tratadas para recuperarem possíveis danos decorrentes da queda. Após essa fase, $50 \%$ dos indivíduos coletados de cada espécie deverão ser encaminhados para comercialização. Os demais deverão ser encaminhados à floresta e fixados nos galhos das árvores portasementes que foram mapeados no censo florestal. As informações obtidas no monitoramento permitirão ajustar o percentual de reintrodução de cada espécie, de acordo com o seu nível de sobrevivência. O monitoramento também permitirá avaliar com maior precisão a viabilidade econômica da atividade. 


\section{Látex de seringueira}

A exploração do látex não obteve bons resultados na análise financeira, ao contrário da produção de couro vegetal. A fim de se obter matéria-prima para o couro vegetal, recomenda-se avaliar a possibilidade de adquirir o látex dos seringais adjacentes à área de manejo. Uma alternativa seria realizar o registro das atividades ligadas ao manejo do seringal nativo, tais como limpeza das árvores, raspagem dos painéis, sangria e coleta do látex, de forma a possibilitar uma avaliação da produtividade e dos custos com dados locais.

Óleo de copaíba

A copaíba é espécie contemplada no Censo Florestal e a sua localização está precisamente registrada. Tal qual a exploração da borracha, a exploração do óleo de copaíba é também plenamente dominada e também deverá apenas sofrer o registro de produção, produtividade e de custos para o seu monitoramento. Na população nativa, alguns indivíduos não produzem óleo, ou produzem muito pouco. Nesses casos, tais indivíduos poderão ser abatidos para produção de madeira em tora. Além da madeira, também será explorada a casca, para comercialização em separado, conforme descrito na classe 3.

\section{Classe 3 de manejo}

Os sete produtos dessa classe são fornecidos por um grande número de espécies. São eles: as cascas (de copaíba, carapanaúba-amarela, cumaru-ferro, pau-d'arco-amarelo, sucupira-amarela, sucuba e jatobá); o jirau, das raízes tabulares de diversas espécies; a seiva do sangue-de-boi, o paú, da decomposição de qualquer fuste, para substrato de vasos de plantas; e os ocos de palmeiras e fustes, para confecção de bueiros e vasos de plantas de diferentes diâmetros e comprimentos.

O jirau, o paú e os fustes ocos são considerados como espécies fictícias, a fim de facilitar o processamento de dados relacionados à sua exploração e monitoramento. Nessa classe não há procedimentos de manejo das espécies-fonte, uma vez que elas já são contempladas nas classes anteriores. Contudo, deverá ser realizado o registro da produção, da produtividade e dos custos, para monitoramento constante da viabilidade da exploração de cada produto.

Cascas

As cascas das espécies selecionadas serão retiradas das toras após o arraste para os pátios de estocagem, antes do seu embarque no caminhão. O seu transporte se dará em paneiros, acondicionados juntamente com os galhos finos explorados na classe 1 .

Raízes tabulares, paú e fustes ocos

As raízes tabulares são aproveitadas das árvores abatidas, portanto sua ocorrência também será definida durante a operação de abate das árvores. O seu transporte, juntamente com o paú e os fustes ocos (seccionados em tamanhos relacionados aos respectivos diâmetros para a confecção de vasos artesanais), será realizado juntamente com galhos finos. O destino desses três produtos será o viveiro florestal, para utilização no próprio viveiro ou comercialização posterior.

Seiva de sangue-de-boi

A seiva do sangue-de-boi deverá ser explorada apenas dos indivíduos encontrados nos locais de construção de estradas, pátios de estocagem e picadas de arraste, quando da sua abertura. A sua coleta se dará em corotes escuros e o seu transporte deverá ser realizado pelo trator de esteiras ou pelo skidder, conforme for o caso.

\section{Monitoramento das atividades}

A constante avaliação da produção, da produtividade e dos custos deverá ser realizada de forma simplificada, por meio da adoção de formulários específicos para cada atividade, que permitam o registro da data, da equipe envolvida, do local (UPA, UT) e hora de início e encerramento. Essas informações deverão ser sistematicamente inseridas no banco de dados, a fim de subsidiarem futuras decisões. 


\section{CONCLUSÕES}

- O método ora proposto, baseado na organização das informações disponíveis dentro e fora da floresta e na análise econômica das alternativas de exploração dos diversos recursos da floresta, pode evitar a escolha de determinadas espécies ou produtos baseada apenas na preferência ou experiência pessoal do elaborador do plano de manejo.

- A restrição da exploração de produtos com baixo nível de informação às faixas destinadas à construção da infraestrutura não aumentará o impacto às espécies-fonte, além do que já ocorreria em função da exploração da madeira.

- A multiplicidade de recursos a serem contemplados no plano de manejo está baseada na consideração de todas as informações disponíveis acerca das espécies e dos seus produtos, independentemente da precisão da fonte. Ao mesmo tempo, o monitoramento dessa exploração permitirá a constante realimentação do banco de dados e melhoria da qualidade e da quantidade da informação.

- O manejo florestal, dessa forma concebido, se contrapõe à limitada classificação dos produtos florestais em madeireiros e não-madeireiros.

- A divisão em classes, ao mesmo tempo em que possibilita a consideração no plano de manejo de todos os produtos da floresta, respeitando a complexidade e o nível de informação preexistente, é mais informativa e completa.

- O perfil econômico ecológico da floresta passa a ser dinâmico, em função do constante aporte de novas informações. Concomitantemente, o nível de conhecimento das espécies e as lacunas de conhecimento podem ser importantes ferramentas para orientação de futuras pesquisas e estabelecimento de prioridades de financiamento.

\section{AGRADECIMENTOS}

À Cia. de Compensados Triunfo, do Mato Grosso e do Acre, ao Valteir Costa e ao Jáderson Mendes, pelas informações prestadas. Fanzeres.

Ao Serviço Florestal Brasileiro, pelo apoio, com especial ênfase à engenheira florestal Anna

Aos amigos José de Arimatéa Silva, Ecio Rodrigues da Silva e Luiz Augusto Mesquita de Azevedo que, embora não tenham participado diretamente desse trabalho, contribuíram sobremaneira com ele, através dos trabalhos e discussões acerca do manejo florestal adequado para a Amazônia.

\section{REFERÊNCIAS}

BRAZ, E. M.; FIGUEIREDO, E. O.; FERREIRA, L. A.; OLIVEIRA, L. C. de; SILVA, Z. A. G. P. da G.; SOUZA, J. M. A. de. Manejo dos produtos florestais não madeireiros da Floresta Estadual do Antimary: a busca de um modelo. In: Congresso Ibero-Americano de pesquisa e desenvolvimento de produtos florestais, 2002, Curitiba, PR.

CAVALCANTI, F. J. de B. Manejo florestal em regime de rendimento sustentado, de uso múltiplo, para a Floresta Estadual do Antimari (Acre). Manaus, 1992. 182 f. Dissertação (Mestrado em Manejo Florestal) - Instituto Nacional de Pesquisas da Amazônia - INPA/Fundação Universidade do Amazonas FUA.

CHICHIGNOUD, M.; DEON, G.; DETIENNE, P.; PARANT, B.; VANTOMME, P. Atlas de maderas tropicales de América Latina. OIMT/CTFT. Abbeville: F. Paillart, 1990.

FREITAS, J. V. de. Improving tree selection for felling and retention in natural forest in Amazonia through spatial control and targeted seed tree retention: a case study of a forest management project in Amazonas state, Brasil. Aberdeen, 2004. 184 f. Tese (Doutorado em Filosofia) - Universidade de Aberdeen, Escócia.

FUNTAC. Fundação de Tecnologia do Estado do Acre - FUNTAC. Relatório do Inventário Florestal Diagnóstico e Plano de Manejo da Fazenda São Jorge. Rio Branco, 2002. 
HIGUCHI, N. Experiências e resultados de intervenções silviculturais na Floresta Tropical Úmida Brasileira. Anais: O Desafio das Florestas Neotropicais. 1991. Curitiba 7 a 12 de abril. Universidade Federal do Paraná.

HOMES, T. P.; BLATE, G. M.; ZWEEDE, J. C.; PEREIRA JÚNIOR, R.; BARRETO, P.; BOLTZ, F. Custos e benefícios financeiros da exploração florestal de impacto reduzido em comparação à exploração florestal convencional na Amazônia Oriental. Belém: Fundação Floresta Tropical, 2002. $69 \mathrm{p}$.

IBAMA/LPF. Instituto Brasileiro do Meio Ambiente e dos Recursos Naturais Renováveis. Laboratório de Produtos Florestais. Madeiras das Amazônia: características e utilização. v. 3 - Amazônia Oriental. Brasília, 1997.

IBDF. Instituto Brasileiro de Desenvolvimento Florestal - IBDF. Estação Experimental de Curuá-Una. Madeiras da Amazônia: características e utilização. 1. v. 2. Brasília: Gráfica do Senado, 1988.

IBDF. Instituto Brasileiro de Desenvolvimento Florestal/CNPq. - v. 1. Floresta Nacional do Tapajós. Madeiras da Amazônia: características e utilização. 1 ed. Brasília: Gráfica do Senado, 1981.

INA. Instituto Nacional de Pesquisas da Amazônia - Coordenação de Pesquisa em Produtos Florestais CPPF. Catálogo de madeiras da Amazônia: característica tecnológica; área da hidrelétrica de Balbina. 1. 1991. Manaus.

IPT. Instituto de Pesquisas Tecnológicas - IPT, São Paulo. Fichas de características das madeiras brasileiras. 2. 1989a. São Paulo: Sec. da Ciência, Tec. e Desenv. Econ. de S. Paulo.

MMA/SUFRAMA/SEBRAE/GTA. Produtos potenciais da Amazônia. Brasília: Prismatic, 1998.

PIÑA-RODRIGUES, F. C. M.; COSTA, L. G. S.; REIS, A. Estratégias de estabelecimento de espécies arbóreas e o manejo de florestas tropicais. In: CONGRESSO FLORESTAL BRASILEIRO, 6., 1990, Campos do Jordão. Anais... 1990. p. 676-684.

RADAMBRASIL. Folhas 19 Rio Branco; geologia, geomorfologia, pedologia, vegetação e uso potencial da terra: v. 12. Departamento Nacional de Produção Mineral. 1976. Rio de Janeiro. 464 p.

RIZZINI, C. T. Árvores e madeiras úteis do Brasil - Manual de dendrologia brasileira. 2.ed. São Paulo: Edgard Blucher Ltda., 1990.

SILVA, J. de A. Quebrando castanha e cortando seringa. Rio de Janeiro, Edur, 2003. 136 p. il.

Análise quali-quantitativa da extração e do manejo dos recursos florestais da Amazônia brasileira: uma abordagem geral e localizada (Floresta Estadual do Antimari-AC). Curitiba (PR): UFPR, 1996 (Tese de doutorado).

SILVA, J. N. M. Manejo de florestas de terra firme da Amazônia brasileira In: Curso de Manejo Florestal Sustentável, 1., 1997, Curitiba. Tópicos em manejo florestal sustentável. Colombo: EMBRAPACNPF, 1997. 253 p. (EMBRAPA-CNPF. Documentos, 34). 59-96.

The behaviour of the tropical rain Forest of the Brazilian Amazon after logging. Tese. Doutorado. 1989. Universidade de Oxford.

SOUZA, A.; CLEMENTE, A. Decisões financeiras e análise de investimentos: fundamentos, técnicas e aplicações. Alceu Souza, Ademir Clemente. 4. ed. São Paulo: Atlas, 2001.

SUDAM/IPT. Superintendência de Desenvolvimento da Amazônia. Departamento de Recursos Naturais. Instituto de Pesquisas Tecnológicas do Estado de São Paulo. Madeiras da Reserva Florestal de CuruáUna, estado do Pará: caracterização anatômica, propriedades gerais e aplicações. 1981. Belém. Publicação IPT n. 204. 
